\title{
Characterization of viscoplasticity behaviour of P91 and P92 power plant steels
}

\author{
A.A. Saad ${ }^{\mathrm{a}, 1_{*}}$, T.H. Hyde ${ }^{\mathrm{a}}$, W. SUN ${ }^{\mathrm{a}}$ and C.J. Hyde ${ }^{\mathrm{a}}$ \\ ${ }^{a}$ Materials, Mechanics and Structures Research Division, Faculty of Engineering, \\ The University of Nottingham, Nottingham NG7 2RD, UK \\ ${ }^{1}$ School of Mechanical Engineering, Universiti Sains Malaysia, 14300 Nibong Tebal, \\ Penang, Malaysia \\ *Corresponding author \\ E-mail address: meaziz@eng.usm.my, Tel: +6045996384, Fax: +6045941025
}

\begin{abstract}
This paper deals with the determination of material constitutive model for P91 and P92 steels at high temperatures. An isothermal, strain-controlled test programme was conducted for both steels for a temperatre range between 400 and $675^{\circ} \mathrm{C}$. The experimental data from these tests were used to obtain the material constants in a viscoplasticity model. The model includes the effects of isotropic and kinematic hardening, as well as time-dependent effects, has been used to model the cyclic material behaviour of each material. Material constants were initially determined from initial cycle stress-strain data, maximum stress evolution data and stress relaxation data. The material constants were improved by use of a least-squares optimisation algorithm. The constitutive models have been implemented into the ABAQUS finite element (FE) code by using the Z-mat software. The performances of the material models for both steels have been assessed by comparing predictions with experimental data obtained from the tests.
\end{abstract}

Keywords: Viscoplasticity model, P91, P92, thermo-mechanical fatigue

\section{Introduction}

The need for power generation industry to improve the thermal efficiency of power plant has led to the development of 9-12\%Cr martensitic steels. The research on P91 and P92 steels started since late 1970s and early 1990s, respectively [1]. Most of research on these materials has focussed on their creep strengths due to its intended application at high temperature. However, understanding the thermo-mechanical behaviour of power plant materials has become more important as the current operation involves more frequent cyclic operation, which has introduced the possibility of thermo-mechanical fatigue (TMF) problems.

The required cyclic operation of power plant due to market forces and competition has increased the concern of researchers on creep-fatigue interaction behaviour. During start up, shut down or load changes of power plant operation, severe thermal gradients between the inside and outside of components due to rapid rates of change of steam temperatures may cause high stress levels to develop [2]. For instance, bore cracking was found in power plant components and which is believed to be associated with thermal fatigue loading [3]. To avoid thermal fatigue, caused by frequent cycling, one solution is to utilise higher creep strength alloy steels for pressure vessel construction [4] so that the thickness of the power plant components can be reduced.

However, the stress-strain behaviour of new power plant components under such conditions needs to be understood first.

The behaviour of power plant components can be simulated using finite element method. For example, the stresses and failure behaviour of pipe weldments under creep condition have been modelled successfully by Hyde et al. [5]. Similar studies have been carried out, for a P91 steel, in order to develop a creep constitutive model with a damage capability [6]. The 
development of these creep constitutive models have contributed to the gaining of better understanding of the material behaviour in such applications as welding process modelling [7] and failure prediction in multiaxial components [8]. The accuracy of the FE modelling works depends on the material constitutive equations. In the TMF conditions, viscoplasticity models are preferred due to their capability of representing both cyclic plasticity and creep behaviour. This type of model is widely used in aeroengine application with nickel base alloys [9]. The material constants can be determined from isothermal tests and the resulting model can be used in anisothermal situations. However, viscoplasticity models are rarely used to represent the behaviour of power plant materials.

In this paper, a material constitutive model is developed to simulate the viscoplasticity behaviour of power plant steels at high temperatures. Estimates of the material constants were initially determined from isothermal strain-controlled test data. Then, the model was improved using a least-squares optimization algorithm. The optimized constants have been implemented in the ABAQUS finite element (FE) code using the Z-mat software in order to compare the model's predictions with TMF experimental data and notched-bar test results.

\section{Experimental procedures}

An Instron 8862 TMF test machine, which utilizes radio-frequency induction heating, was used to perform all experiments. The coil design enables the temperature gradient along the gauge section to be controlled to within $\pm 10^{\circ} \mathrm{C}$ of the target temperature. The maximum achievable load for the machine is $35 \mathrm{kN}$. The machine is controlled by a servo electric screw driven actuator. Strains were measured using high temperature extensometers with a gauge length of $12.5 \mathrm{~mm}$.

The materials used in this work were 9\%Cr steel alloys, namely P91 and P92 steels. The materials provided were from power plant steam pipe sections. The P91 and P92 pipes had outer diameters of $298.5 \mathrm{~mm}$ and $355 \mathrm{~mm}$, respectively, and wall thicknesses of $55 \mathrm{~mm}$ and $30 \mathrm{~mm}$, respectively. The $\mathrm{P} 91$ steel was austenized at $1060^{\circ} \mathrm{C}$ for 45 minutes and tempered at $760^{\circ} \mathrm{C}$ for 2 hours. The P92 steel was austenized at $1070^{\circ} \mathrm{C}$ for 45 minutes and tempered at $780^{\circ} \mathrm{C}$ for 108 minutes. The chemical compositions of the two materials are given in Table 1.

The test specimens were machined from the P91 and P92 steam pipe sections and 3 specimen geometries were used in the study. For the tests carried out under isothermal condition, a solid specimen was used as shown in Fig. 1(a). The gauge section of the solid specimen is $15 \mathrm{~mm}$ in length and $6.5 \mathrm{~mm}$ in diameter. For some specimens, a $4 \mathrm{~mm}$ diameter hole was drilled through the specimen as shown by dotted line in Fig. 1(a). This hollow specimen was used in anisothermal tests in order to reduce temperature difference through specimen wall. Fig. 1(b) shows the modification of the middle section of the solid specimen to create a $2 \mathrm{~mm}$ notch radius in order to study the multiaxial behaviour effects. The dimensions of both end sections are the same as the solid specimen.

Table 1. Chemical compositions of the P91 and P92 steels (wt\%).

\begin{tabular}{lllllllllllll}
\hline & $\mathrm{Cr}$ & $\mathrm{Mo}$ & $\mathrm{C}$ & $\mathrm{Si}$ & $\mathrm{S}$ & $\mathrm{P}$ & $\mathrm{Al}$ & $\mathrm{V}$ & $\mathrm{Nb}$ & $\mathrm{N}$ & $\mathrm{W}$ & $\mathrm{B}$ \\
\hline P91 & 8.60 & 1.02 & 0.12 & 0.34 & $<0.002$ & 0.017 & 0.007 & 0.24 & 0.070 & 0.060 & 0.03 & - \\
$\mathrm{P} 92$ & 8.62 & 0.33 & 0.10 & 0.45 & 0.002 & 0.015 & 0.019 & 0.21 & 0.076 & 0.047 & 1.86 & 0.0034 \\
\hline
\end{tabular}

Fully-reversed isothermal tests were conducted at several temperatures under strain control with a total strain amplitude of $\pm 0.5 \%$ and with a strain rate of $0.1 \% / \mathrm{s}$, as shown in Fig. 1(c). The testing temperatures are between $400-600^{\circ} \mathrm{C}$ and $500-675^{\circ} \mathrm{C}$, respectively. The cyclic 
period is 20 s for the continuous strain cycling tests. The tests were carried out to failure, defined as the number of cycles at which a 30 percent drop in the maximum stress occurs. Tests with dwell periods at the tensile peak strains for times of 2 and 5 minutes were also applied to P91 and P92 specimens, respectively, in order to get stress relaxation data for the materials. The strain amplitudes and strain rates were maintained constant throughout the tests.

Two additional types of tests were conducted in order to verify the material model. Firstly, thermo-mechanical fatigue tests were implemented by controlling the cyclic mechanical strain and temperature. A mechanical strain range of $\pm 0.5 \%$ was used for all of the thermo-mechanical fatigue tests. Two temperature ranges of $400-500^{\circ} \mathrm{C}$ and $400-600^{\circ} \mathrm{C}$ were implemented in the P91 TMF tests while temperature range of $500-675^{\circ} \mathrm{C}$ was used for the P92 TMF tests. The TMF tests were carried out under in-phase loading conditions (maximum temperature at maximum strain) up to failure and out-of-phase loading conditions (minimum temperature at maximum strain) as shown in Fig. 1(d). All of the TMF tests were carried out with a period of 60 s per cycle.

Secondly, an isothermal fully reversed load-controlled test using a notched bar specimen was implemented at $600^{\circ} \mathrm{C}$ in order to produce data to verify the capability of the material model under multiaxial conditions. The nominal stress amplitude is $300 \mathrm{MPa}$ on the minimum notch section and the load was cycled in a 20 seconds period.
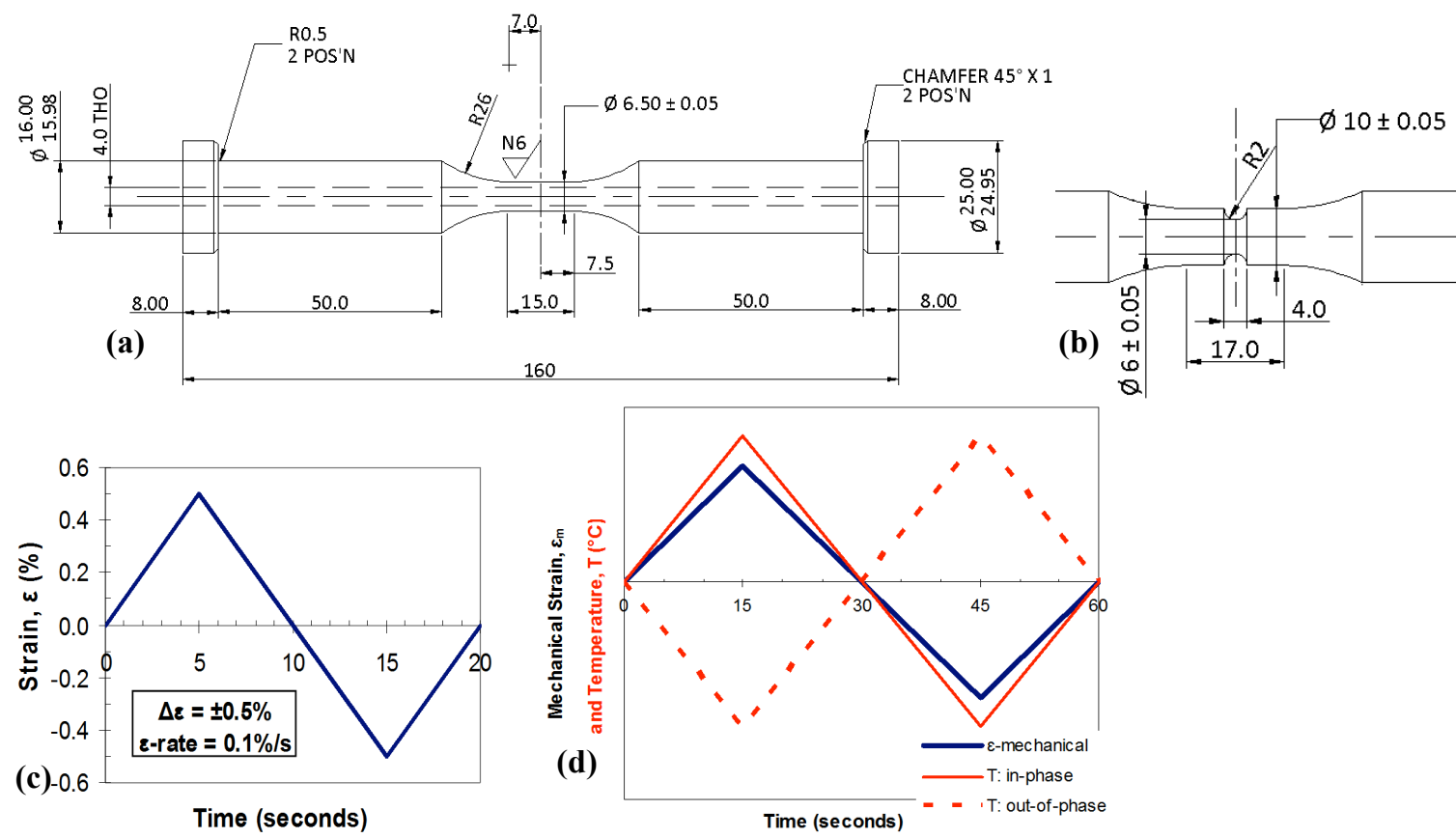

Fig. 1. The specimen geometry used in the experiment with (a) solid and hollow dimension and (b) the modification of the gauge length section to produce notched-bar specimen. (c) The sawtooth type waveforms used in the isothermal tests and (d) schematic representation of the TMF tests with in-phase and out-of-phase temperature cycles.

\section{Material model characterization}

\subsection{The material model}

The Chaboche unified viscoplasticity model [10] was chosen to model the behaviour of the P91 and P92 steels. The inelastic strain rate, $\dot{\varepsilon}_{\mathrm{p}}$, of the model is given by the following equations: 
$\dot{\varepsilon}_{\mathrm{p}}=\left\langle\frac{f}{\mathrm{Z}}\right\rangle^{\mathrm{n}} \operatorname{sgn}(\sigma-\chi)$

$\operatorname{sgn}(x)=\left\{\begin{array}{ll}1, & x>0 \\ 0, & x=0 \\ -1, & x<0\end{array}\right.$ and $\quad\langle x\rangle= \begin{cases}x, & x>0 \\ 0, & x \leq 0\end{cases}$

$f=|\sigma-\chi|-\mathrm{R}-\mathrm{k}$

$\mathrm{Z}$ and $\mathrm{n}$ are material constants, $\sigma$ is the applied stress, $\mathrm{k}$ is the initial cyclic yield stress, $\chi$ is the kinematic hardening parameter and $\mathrm{R}$ is the isotropic hardening parameter. The evolutions of the various parameters in the model are given by:

$$
\begin{aligned}
& \dot{\chi}_{\mathrm{i}}=\mathrm{C}_{\mathrm{i}}\left(\mathrm{a}_{\mathrm{i}} \dot{\varepsilon}_{\mathrm{p}}-\chi_{\mathrm{i}} \dot{\mathrm{p}}\right) \\
& \chi=\chi_{1}+\chi_{2} \\
& \mathrm{R}=\mathrm{Q}\left(1-\mathrm{e}^{-\mathrm{bp}}\right) \\
& \sigma_{\mathrm{v}}=\mathrm{Z} \dot{\mathrm{p}}^{1 / \mathrm{n}} \\
& \dot{\mathrm{p}}=\left|\dot{\varepsilon}_{\mathrm{p}}\right|
\end{aligned}
$$

where $\sigma_{v}$ is the viscous stress; $p$ is the accumulated viscoplastic strain; $a_{i}$ and $C_{i}(i=1,2)$ represent the stationary values of $\chi_{i}$ and the speed to reach the stationary values, respectively; $Q$ is the asymptotic value of the isotropic variable, $R$, at the stabilized cyclic condition and $b$ governs the stabilization rate. The applied stress can be decomposed as

$$
\sigma=\chi+\left(\mathrm{R}+\mathrm{k}+\sigma_{\mathrm{v}}\right) \operatorname{sgn}(\sigma-\chi)=\mathrm{E}\left(\varepsilon-\varepsilon_{\mathrm{p}}\right)
$$

The equations described above are in the uniaxial form of the viscoplasticity model which consists of ten temperature dependent material properties, namely E, k, Q, b, a $\mathrm{a}_{1}, \mathrm{C}_{1}, \mathrm{a}_{2}, \mathrm{C}_{2}, \mathrm{Z}$ and n.

\subsection{Identification of the viscoplasticity model constants}

The constants of the viscoplasticity model can be initially determined by using a step-bystep procedure on the first quarter of isothermal cyclic test data as explained in [11]. These constants can be used to reasonably accurately predict the stress-strain behaviour of P91 and P92 steels. However, the way in which the initial material constants have been determined does not take into account the interactions which take place between the various hardening (kinematic and isotropic) behaviour and the creep relaxation behaviour of the material. Thus, a simultaneous procedure was further used in this study to obtain optimized constants in order to improve the stress-strain predictions of the model. An optimisation program developed by Gong et al. [12] was used for this purpose.

The optimisation method is based on a least squares algorithm. The principle of the optimisation is to search for the global minimum of the differences between the predicted and experimental stresses. It is described mathematically by an objective function, $F(x)$, as follows:

$F(x)=\sum_{j=1}^{N} w_{j} F_{j}(x)=\frac{1}{2} \sum_{j=1}^{N} w_{j} \sum_{i=1}^{M_{j}}\left(A(x)_{i j}^{\text {pre }}-A_{i j}^{\exp }\right)^{2}$ 
$w_{j}=\frac{\sum_{j}^{N} M_{j}}{M_{j} \max \left|A_{i j}^{\exp }\right|}$

where $A(x)_{i j}^{p r e}$ and $A_{i j}^{\text {exp }}$ represent the predicted and the corresponding measured stresses, respectively. $x$ is the optimisation variable set consisting of the full set of material model constants. $N$ is the number of experimental data types, which is 3 for this program namely stressstrain loops, peak stresses and relaxation data. $M_{j}$ is the total number of data points in each $j^{\text {th }}$ type of experiment data. A weight factor, $w_{j}$, is used to control the contributions of each objective function.

The optimisation program was implemented, using Matlab. The nonlinear least squares optimisation function, lsqnonlin, is provided within the Matlab optimisation Toolbox. The ODE45 function is used to solve the first order system of differential equations to calculate the predicted stress value at the end of subinterval. In order to avoid converging to a local minimum rather than the intended global minimum, the first step is to obtain a first set of optimum parameters, by the least squares method, starting from the initially estimated set of parameters. These sets of optimum parameters are then perturbed by a finite amount to investigate whether a better minimum is achieved or whether the parameter returns to the same value. This process is repeated until the same minimum is returned from a series of restart positions as shown in Fig. 2. The optimized constants for the P91 and P92 steels are given in Table 2 and Table 3, respectively.

Table 2. The optimized constants of viscoplasticity model for P91 steels at 400,500 and $600^{\circ} \mathrm{C}$.

\begin{tabular}{|c|c|c|c|c|c|c|c|c|c|c|}
\hline $\begin{array}{l}\mathrm{T} \\
\left({ }^{\circ} \mathrm{C}\right)\end{array}$ & $\begin{array}{l}\mathrm{E} \\
(\mathrm{MPa})\end{array}$ & $\begin{array}{l}\mathrm{k} \\
(\mathrm{MPa})\end{array}$ & $\begin{array}{l}\mathrm{Q} \\
(\mathrm{MPa})\end{array}$ & b & $\begin{array}{l}\mathrm{a}_{1} \\
(\mathrm{MPa})\end{array}$ & $\mathrm{C}_{1}$ & $\begin{array}{l}\mathrm{a}_{2} \\
(\mathrm{MPa})\end{array}$ & $\mathrm{C}_{2}$ & $\begin{array}{l}\mathrm{Z} \\
\left(\mathrm{MPa} \cdot \mathrm{s}^{1 / \mathrm{n}}\right)\end{array}$ & $\mathrm{n}$ \\
\hline 400 & 185000 & 151 & -45 & 0.4 & 183 & 1000 & 200 & 40 & 1250 & 2.48 \\
\hline 500 & 174228 & 120 & -65 & 0.7 & 130 & 1000 & 120 & 45 & 1200 & 3.01 \\
\hline 600 & 140000 & 90 & -70 & 1.1 & 70 & 900 & 100 & 50 & 1000 & 3.48 \\
\hline
\end{tabular}

Table 3. The optimized constants of viscoplasticity model for P92 steels at 500, 600 and $675^{\circ} \mathrm{C}$.

\begin{tabular}{lllllllllll}
\hline $\mathrm{T}$ & $\mathrm{E}$ & $\mathrm{k}$ & $\mathrm{Q}$ & $\mathrm{b}$ & $\begin{array}{l}\mathrm{a} 1 \\
(\mathrm{MPa})\end{array}$ & $\mathrm{C} 1$ & $\begin{array}{l}\mathrm{a} 2 \\
(\mathrm{MPa})\end{array}$ & $\mathrm{C} 2$ & $\begin{array}{l}\mathrm{Z} \\
(\mathrm{MPa} . \mathrm{s} 1 / \mathrm{n})\end{array}$ & $\mathrm{n}$ \\
\hline 500 & 175000 & 150 & -66 & 0.8 & 80 & 2000 & 128 & 300 & 2257 & 2.35 \\
600 & 149987 & 94 & -80 & 0.99 & 81.2 & 800 & 100 & 50 & 1051.3 & 3.5 \\
675 & 115000 & 40 & -50 & 0.70 & 30 & 300 & 10 & 500 & 1000 & 3.7 \\
\hline
\end{tabular}




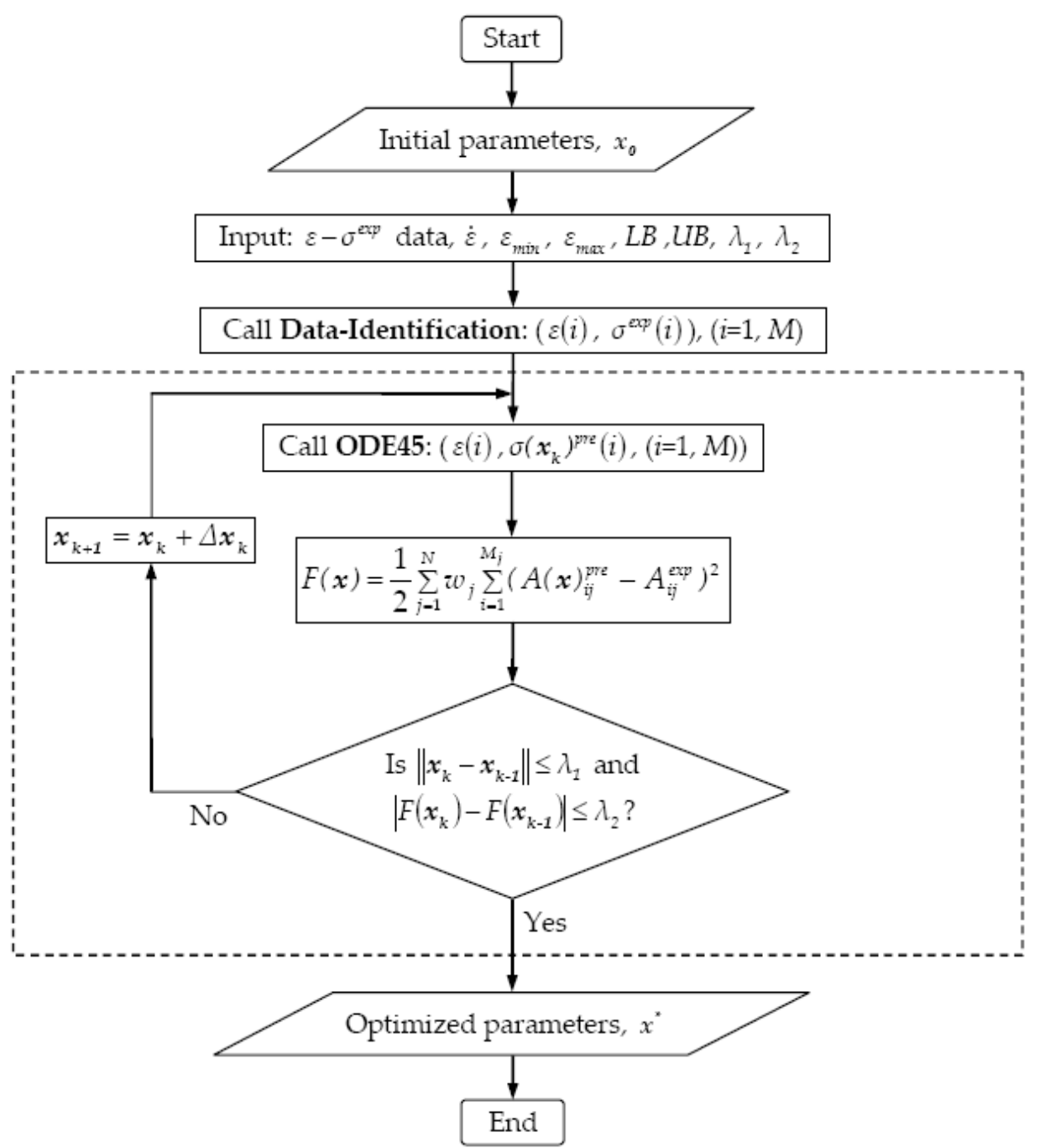

Fig. 2. The process flowchart in determining the optimised constants using the nonlinear least squares algorithm in Matlab [13].

\subsection{Two stages of isotropic hardening}

Use of the optimised set of constants, which include the nonlinear isotropic hardening, enables good stress-strain predictions to be obtained for the P91 and the P92 steels. However, the shape of the peak stress evolution prediction, up to the end of the second stage of cyclic softening, is unrealistic as compared to the experimental data in which the rate of peak stress evolution becomes zero when the specimen reaches a certain number of cycles. From the experimental data, the rate of peak stress evolution is almost constant in the second stage of cyclic softening as shown in Fig. 3(a).

In this study, the isotropic hardening model as shown in equation (6) is further modified by adding a linear term [14] as given by following equation:

$$
\mathrm{R}=\mathrm{Hp}+\mathrm{Q}\left(1-\mathrm{e}^{-\mathrm{bp}}\right)
$$

where $\mathrm{Hp}$ is the linear term. $\mathrm{H}$ is a constant and the linear term corresponds to the slope for the second stage of cyclic softening [15], as shown in Fig. 3(a). All of the constants previously determined by the optimisation programme remain the same except constants $Q$ and $b$ which represent stage 1 of the cyclic softening. Q can be estimated as the difference between point $\mathrm{X}$ 
and the maximum stress at first cycle in Fig. 3(a) while b is the speed to reach the maximum stress at the end of stage 1 . The accumulated plastic strain, $p$, can be taken to be $2 \Delta \varepsilon_{\mathrm{p}} \mathrm{N}$ and thus the constant $\mathrm{H}$ can be estimated as the slope of the second stage of cyclic softening which is equal to $2 \Delta \varepsilon_{\mathrm{p}} \mathrm{H}$. The material constants for the combined linear and nonlinear isotropic hardening are given in Table 4. Fig. 3(b) shows an improved cyclic softening evolution prediction of the combined linear nonlinear model, equation (12), as compared to the nonlinear isotropic hardening model, equation (6).
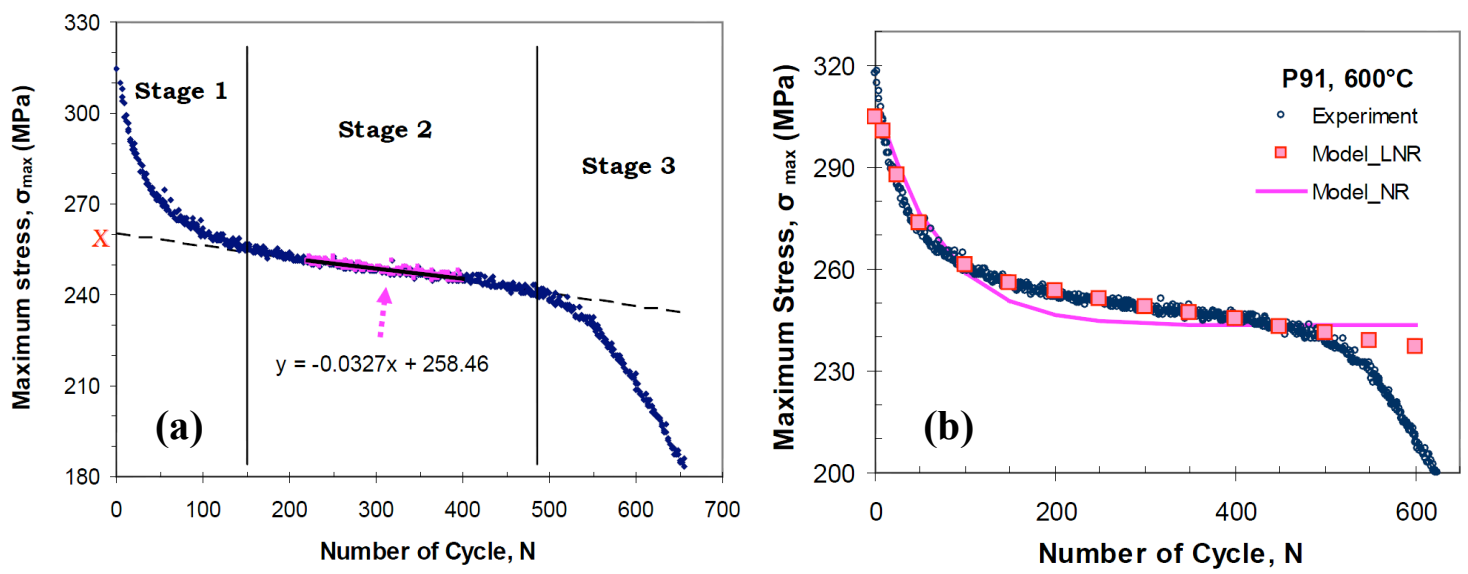

Fig. 3. (a) Example of determination of material constants for the combined linear and nonlinear (LNR) isotropic hardening model for P91 steel at $600^{\circ} \mathrm{C}$ and (b) the comparison of the maximum stress evolution prediction between nonlinear (NR) and the LNR model.

Table 4. The material constants of the combined linear and nonlinear isotropic hardening model for P91 and P92 steels at different temperatures.

\begin{tabular}{lllllll}
\hline \multirow{2}{*}{ Constants } & \multicolumn{3}{c}{ P91 steel } & \multicolumn{3}{c}{ P92 steel } \\
\cline { 2 - 7 } & $400{ }^{\circ} \mathrm{C}$ & $500^{\circ} \mathrm{C}$ & $600{ }^{\circ} \mathrm{C}$ & $500^{\circ} \mathrm{C}$ & $600^{\circ} \mathrm{C}$ & $675^{\circ} \mathrm{C}$ \\
\hline $\mathrm{Q}$ & -30 & -42 & -52 & -52 & -58 & -40 \\
$\mathrm{~b}$ & 0.8 & 1.3 & 1.9 & 1.1 & 1.6 & 1.2 \\
$\mathrm{H}$ & -1.8 & -2.1 & -2.9 & -2.7 & -2.7 & -1.6 \\
\hline
\end{tabular}

\section{Results and discussions}

In this section, comparisons between finite element simulation results of axisymmetric models using Abaqus for the three types of specimen and their experimental results are presented. The optimized viscoplasticity constants were used in the simulation and the model was implemented into Abaqus by using Z-mat software. The isothermal strain-controlled simulations were implemented using a model based on the gauge section of a cylindrical specimen with a diameter of $6.5 \mathrm{~mm}$ and a gauge length of $12.5 \mathrm{~mm}$. Displacement control was applied in order to get the same strain range as that for the experimental data. For anisothermal conditions, the temperature was applied for the whole specimen geometry. The coefficient of thermal expansion for the P91 and the P92 steels, which are $14.5 \times 10^{-6} /{ }^{\circ} \mathrm{C}$ and $14.9 \times 10^{-6} /{ }^{\circ} \mathrm{C}$, respectively, determined from TMF test results, were applied to include the effect of thermal strain on the total strain value. A quarter model of the P91 notched specimen was used to simulate the notched bar specimen and the same loading of $\pm 300 \mathrm{MPa}$, as was used for the test, was applied cyclically. The cyclic period for each simulation is identical to its testing period. 
Some typical results obtained from the isothermal strain-controlled tests of the P91 and P92 steels are shown in Figs. 4 and 5. It can be seen that both steels have shown similar stressstrain behaviours throughout the tests with cyclic softening behaviour for all testing temperatures. The P92 steel has slightly higher stress values than those of the P91 steel for the same strain range, as can be seen in Fig. 4(a) and 4(b). Similar trends in stress level comparison for P91 and P92 steels have also been reported by Vaillant et al. [16]. Fig. 4(b) shows typical stress-strain loops in the end stage of the tests during which a "hysteresis loop tail" can be seen at the bottom of compression data, which indicates the occurrence of cracks [17]. In general, the P92 steel exhibits better fatigue life behaviour based on the tension-compression test results. The addition of dwell periods causes a stress relaxation for both steels, as shown in Fig. 5(a). The difference in short dwell periods for the P91 and the P92 tests seems to have no significant effect on the cycles to failure, see Fig. 5(b).
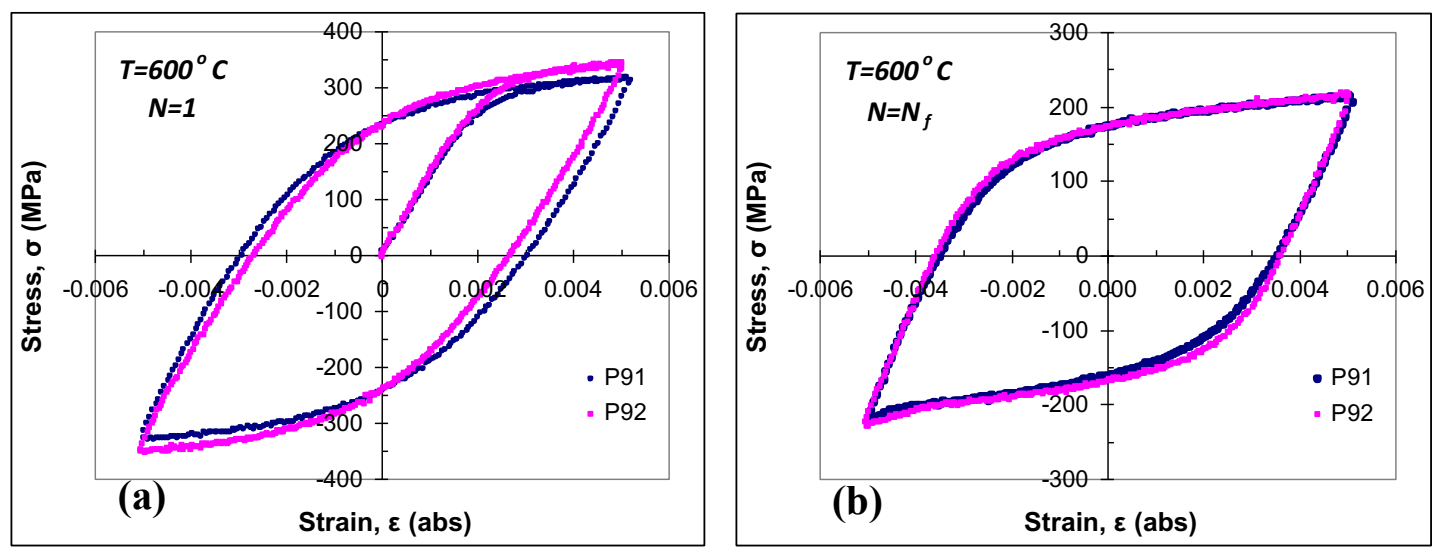

Fig. 4. Comparison of stress-strain behaviour for $\mathrm{P} 91$ and $\mathrm{P} 92$ steels at $600^{\circ} \mathrm{C}$ for (a) the first cycle and (b) the last cycle recorded indicating the "hysteresis loop tail" at the base of compressive stress part of the loop.
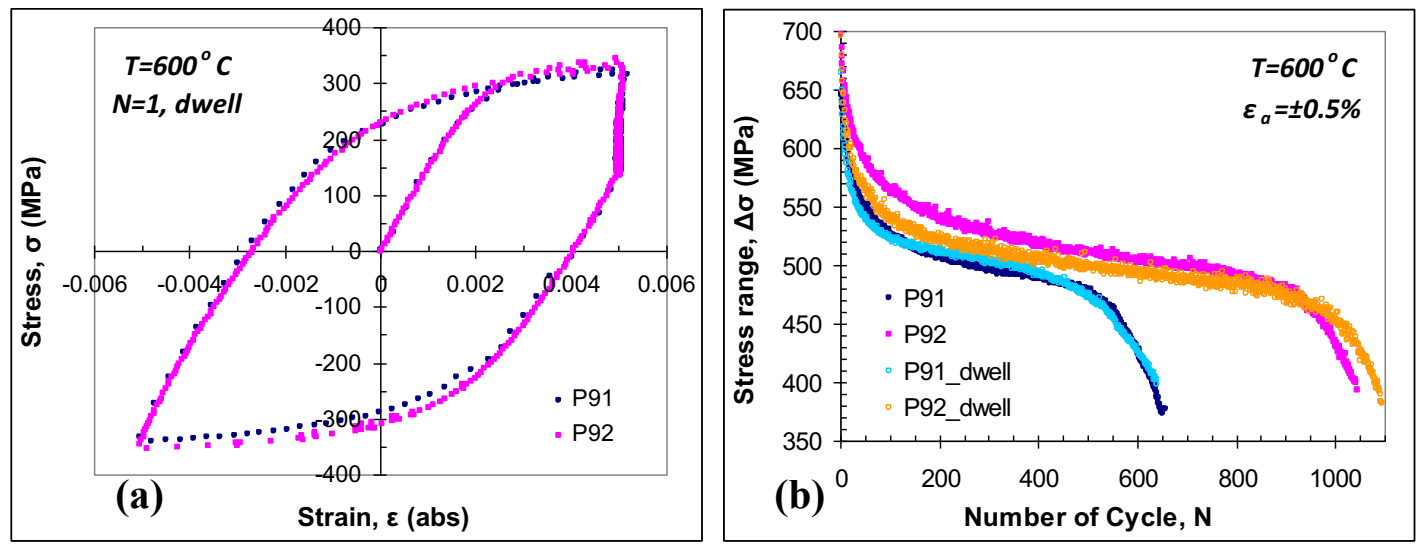

Fig. 5. (a) The stress-strain data at the first cycle for the test with dwell period and (b) the evolution of stress range during tension-compression and dwell test of P91 and P92 steels.

The finite element simulation results of isothermal loading using the optimized viscoplasticity model show good comparison to experimental data for the P91 and the P92 steels. The shapes of the predicted stress-strain loops and the peak stresses are in very good agreement with the test data, as shown in Figs. 6 (a) and (b). Also, the simulation of tension-compression at lower strain amplitude, i.e. $0.25 \%$, shows good comparison to the test data, as shown in Fig. 7, although the viscoplasticity constants have been determined from the test data with larger strain amplitudes. 

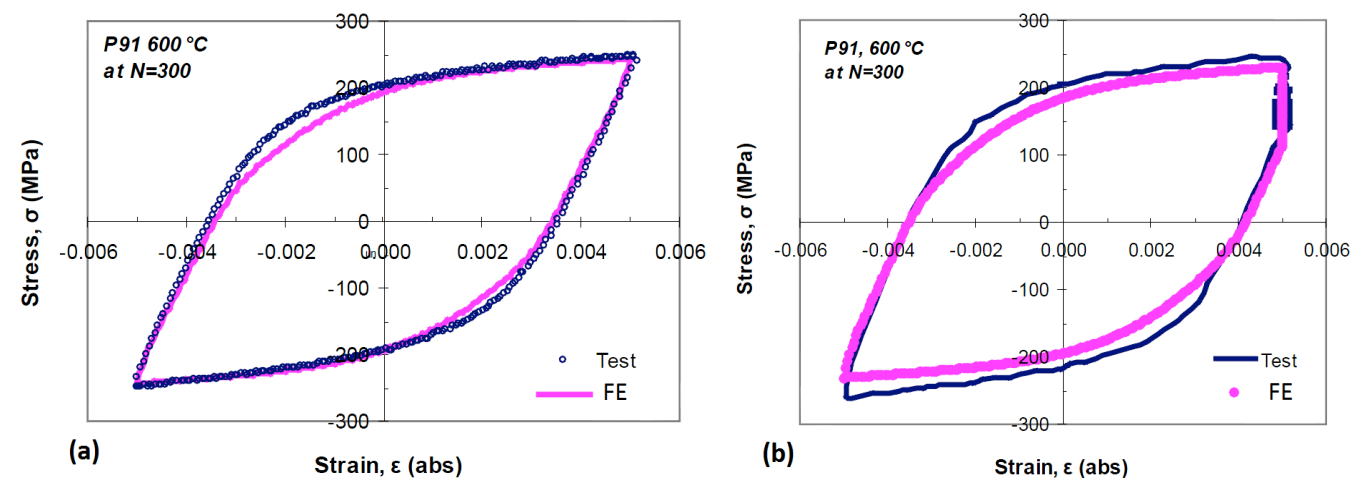

Fig. 6. The comparison of stress-strain relationship of the $\mathrm{P} 91$ steel at $600^{\circ} \mathrm{C}$ during $300^{\text {th }}$ cycle between experimental data and FE prediction using the viscoplasticty constants for (a) the tension-compression test and (b) the test with holding period.
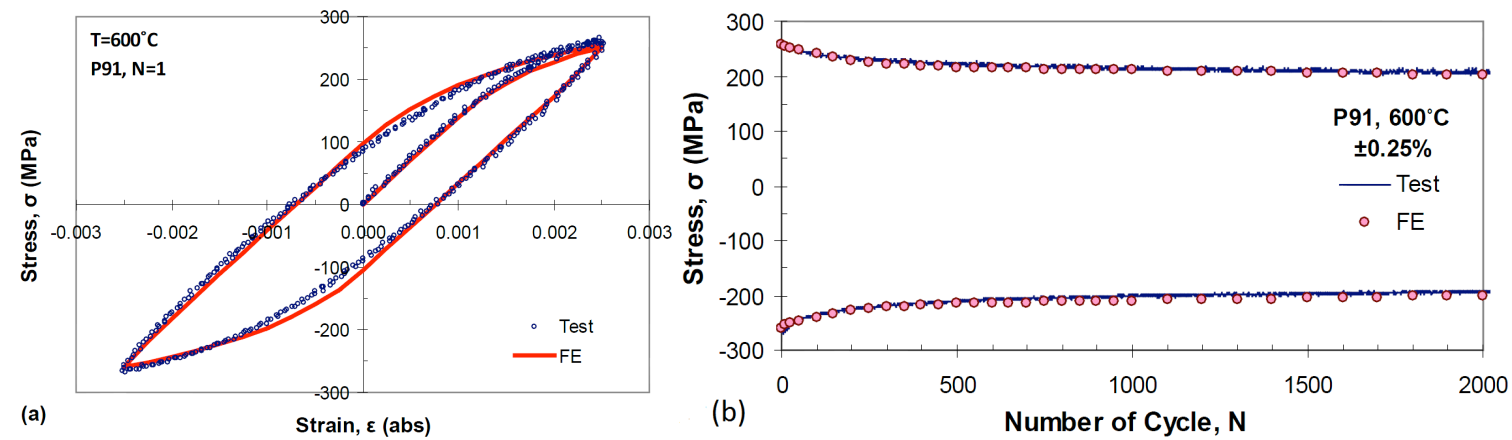

Fig. 7. Comparison of the test and the FE simulation results for the P91 steel, isothermal straincontrolled test of $\pm 0.25 \%$ amplitude at $600^{\circ} \mathrm{C}$, for (a) the first cycle and (b) the evolution of maximum and minimum stresses up to $2000^{\text {th }}$ cycle.

The viscoplasticity model of the P91 and the P92 steels also perform well in predicting the thermo-mechanical fatigue. For example, the FE prediction of the in-phase and the out-of-phase TMF loading are generally in good agreement with experimental data as shown in Figs. 8 (a) and (b), respectively. The model also gives the cyclic softening behaviour in TMF conditions. It has been observed in TMF test with temperature ranges of $400-600^{\circ} \mathrm{C}$ and $500-600^{\circ} \mathrm{C}$ that the stress levels become stable when the test temperature exceeds $500^{\circ} \mathrm{C}$. This observation may correspond to the creep phenomenon which is important at high temperature. Fig. 8(b) shows the TMF loop for the test with temperature below $500^{\circ} \mathrm{C}$ and it can be seen that the shapes of the loop at the tensile and compressive stress are similar without stress stabilization.
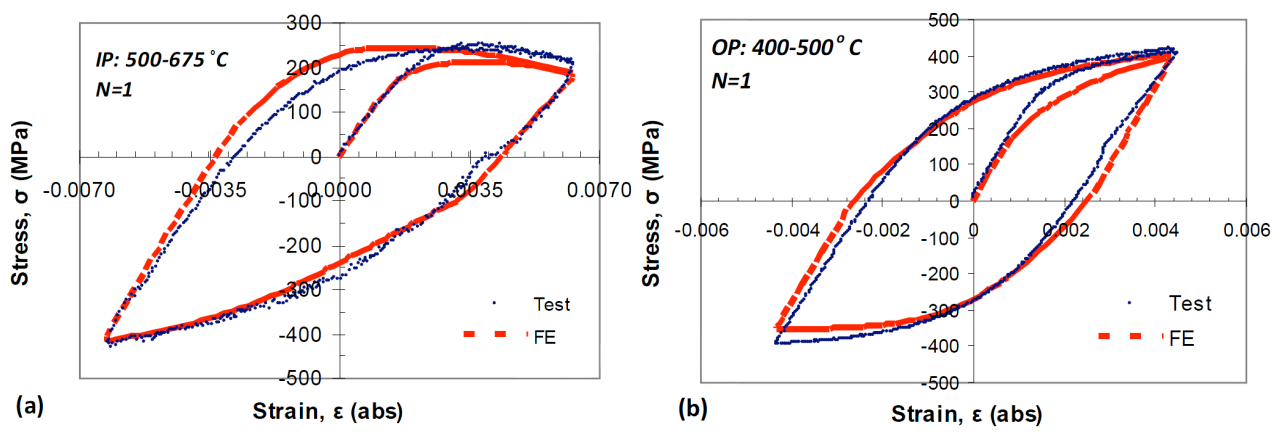

Fig. 8. Comparison of the test and the FE simulation results under TMF loading for (a) the P92 steel between 500 and $675^{\circ} \mathrm{C}$ temperature with in-phase loading and (b) the P91 steel between 400 and $500^{\circ} \mathrm{C}$ with out-of-phase loading at first cycle. 
Fig. 9(a) shows the simulation results of the analysis of the notched bar specimen at the end of the first complete loop. The maximum von-Mises stress (red-contour) is located at the notch root of the specimen. The notch root area is the critical area of the specimen as the fracture of the specimen occurs in this area. The stress-strain simulation results in different directions at the location of the notch root, indicated by point A, are shown in Fig. 9(b). From the figure, it is clear that the stress-strain response in the 22-direction, which is the loading direction, is the most significant direction in the simulation and the loop indicates clearly the effect of plasticity at the notch root position. In the same figure, one of the extensometer arms is illustrated by the grey pin and located at $6.25 \mathrm{~mm}$ from the centre line. The nodal stress-strain results at the tip of the extensometer arm reveal linear stress-strain behaviour in all directions as shown in Fig. 9(c). The displacement of the extensometer in the actual tests is the only parameter that can be used for comparison to the finite element calculation. Fig. 10 shows the FE predicted displacement of the extensometer point up to 1000 cycles and the prediction is in good agreement with the experimental data. After 1000th cycle, the displacement in the actual test increased rapidly due to propagation of cracks which the current material model does not include.
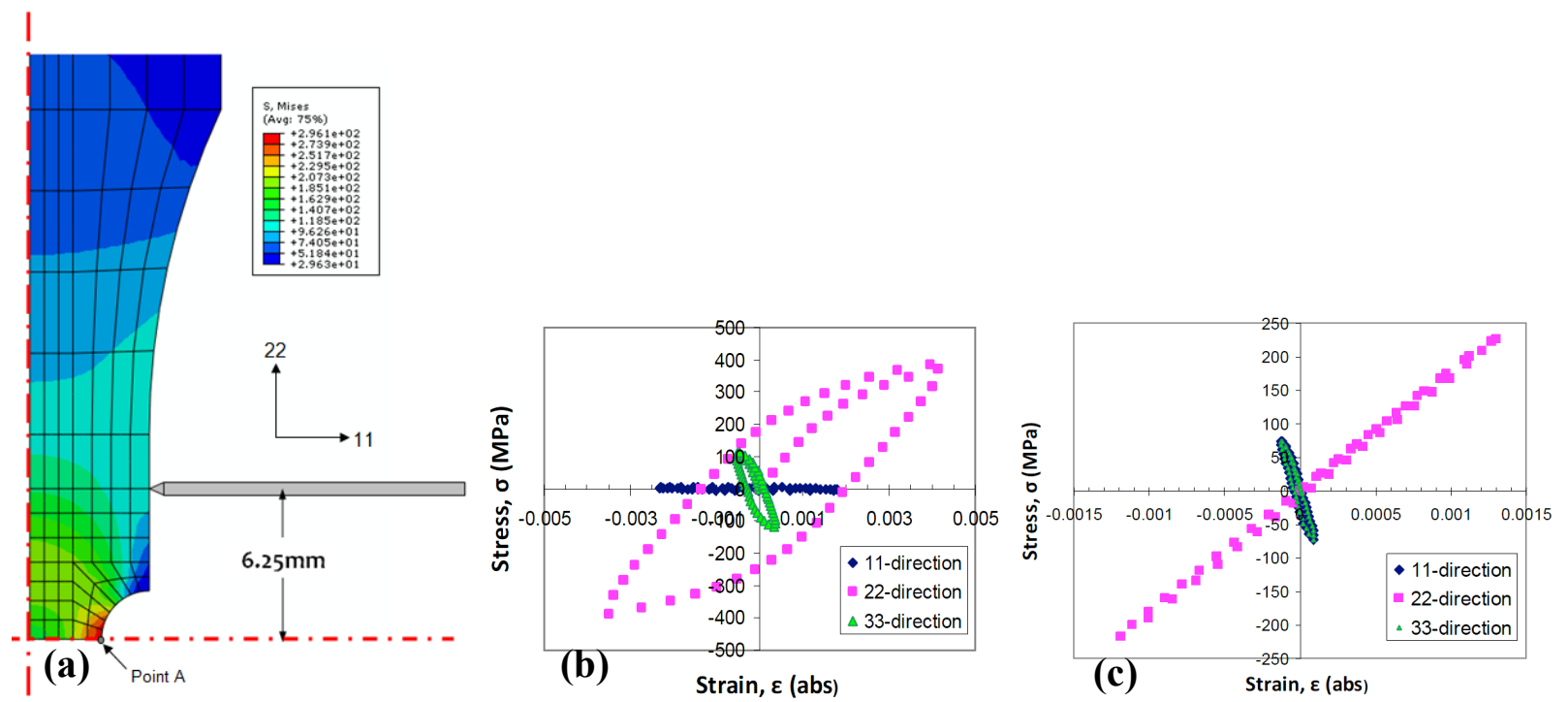

Fig. 9. (a) The P91 notched bar FE simulation result at $600^{\circ} \mathrm{C}$ with the nodal stress-strain loops at (b) point $\mathrm{A}$ (notch root) and (c) the extensometer arm location.

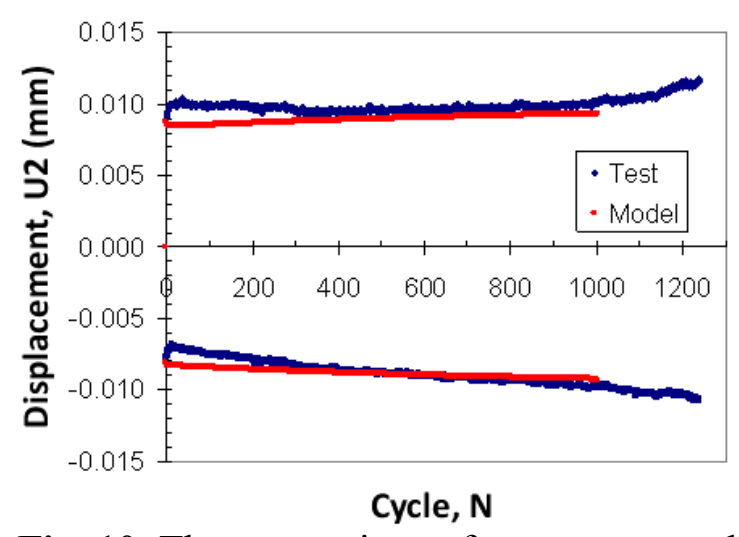

Fig. 10. The comparison of extensometer displacement in the test and the nodal displacement of the same location in the FE simulation for the fully reversed load-controlled condition. 


\section{Conclusions}

The material constitutive model for the P91 and the P92 steels under cyclic loading and high temperature conditions have been developed in this study. The stress-strain predictions have shown good comparison to experimental data, particularly in temperature range of 400 to $600^{\circ} \mathrm{C}$ and 500 to $675^{\circ} \mathrm{C}$ for the P91 and the P92 steels, respectively. The results of TMF and notchedbar simulations show promising predictive capability which indicates that the model can be used in temperature cycling conditions and under multiaxial stress states.

\section{Acknowledgements}

The authors would like to acknowledge the support of The Energy Programme, which is a Research Councils UK cross council initiative led by EPSRC and contributed to by ESRC, NERC, BBSRC and STFC, and specifically the Supergen initiative (Grants GR/S86334/01 and EP/F029748) and the following companies; Alstom Power Ltd., Doosan Babcock, E.ON, National Physical Laboratory, Praxair Surface Technologies Ltd, QinetiQ, Rolls-Royce plc, RWE npower, Siemens Industrial Turbomachinery Ltd. and Tata Steel, for their valuable contributions to the project.

\section{References}

[1] Ennis PJ, Czyrska-Filemonowicz A. Recent advances in creep-resistant steels for power plant applications. Sadhana - Academy Proceedings in Engineering Sciences. 2003;28:709-30.

[2] Shibli A, Starr F. Some aspects of plant and research experience in the use of new high strength martensitic steel P91. International Journal of Pressure Vessels and Piping. 2007;84:11422.

[3] Brett SJ. Service experience of weld cracking in CrMoV steam pipework systems. 2nd International Conference Integrity og High Temperature Welds. London2003. p. 3-17.

[4] Shibli A. Performance of modern high strength steels (P91, P92) in high temperature plant. 2008. p. 161-70.

[5] Hyde TH, Sun W, Williams JA. Creep analysis of pressurized circumferential pipe weldments - A review. Journal of Strain Analysis for Engineering Design. 2003;38:1-30.

[6] Hyde TH, Becker AA, Sun W, Williams JA. Finite-element creep damage analyses of P91 pipes. International Journal of Pressure Vessels and Piping. 2006;83:853-63.

[7] Yaghi AH, Hyde TH, Becker AA, Sun W. Finite element simulation of welding and residual stresses in a P91 steel pipe incorporating solid-state phase transformation and post-weld heat treatment The Journal of Strain Analysis for Engineering Design. 2008; Volume 43:275-93. [8] Hayhurst DR, Lin J, Hayhurst RJ. Failure in notched tension bars due to high-temperature creep: Interaction between nucleation controlled cavity growth and continuum cavity growth. International Journal of Solids and Structures. 2008;45:2233-50.

[9] Yaguchi M, Yamamoto M, Ogata T. A viscoplastic constitutive model for nickel-base superalloy, part 1: kinematic hardening rule of anisotropic dynamic recovery. International Journal of Plasticity. 2002;18:1083-109.

[10] Chaboche JL, Rousselier G. On the Plastic and Viscoplastic Constitutive Equations - Part 1: Rules Developed With Internal Variable Concept. Journal of Pressure Vessel Technology. 1983;105:153-9.

[11] Saad AA, Hyde CJ, Sun W, Hyde TH. Thermal-mechanical fatigue simulation of a P91 steel in a temperature range of $400-600^{\circ} \mathrm{C}$. Materials at High Temperatures. 2011;28:212-8.

[12] Gong YP, Hyde CJ, Sun W, Hyde TH. Determination of material properties in the Chaboche unified viscoplasticity model. Proceedings of the Institution of Mechanical Engineers, Part L: Journal of Materials: Design and Applications 2010;224:19-29. 
[13] Hyde CJ. Thermo-mechanical fatigue and creep of high temperature materials: University of Nottingham; 2010.

[14] Lemaitre J, Chaboche J-L. Mechanics of Solid Materials. 3rd ed. Cambridge: Cambridge University Press; 2000.

[15] Bernhart G, Moulinier G, Brucelle O, Delagnes D. High temperature low cycle fatigue behaviour of a martensitic forging tool steel. International Journal of Fatigue. 1999;21:179-86. [16] Vaillant JC, Vandenberghe B, Hahn B, Heuser H, Jochum C. T/P23, 24, 911 and 92: New grades for advanced coal-fired power plants--Properties and experience. International Journal of Pressure Vessels and Piping. 2008;85:38-46.

[17] Dunne FPE, Makin J, Hayhurst DR. Automated procedures for the determination of high temperature viscoplastic damage constitutive equations. Proceedings of the Royal Society:

Mathematical and Physical Sciences. 1992;437:527-44. 